\title{
Inhibition of Cell Proliferation and MAP Kinase and Akt Pathways in Oral Squamous cell Carcinoma by Genistein and Biochanin A
}

\author{
Tara L. Johnson, Maria B. Lai, James C. K. Lai and Alok Bhushan \\ Department of Biomedical and Pharmaceutical Sciences, College of Pharmacy and Biomedical Research Institute, \\ Idaho State University, Pocatello, Idaho, USA
}

\begin{abstract}
High morbidity and mortality associated with oral squamous cell carcinoma (OSCC) are largely attributable to late stage diagnosis. Despite significant advances in therapeutic strategies, the five-year survival rate for oral cancer remains at about $50 \%$. A chemopreventive approach may be an effective alternative or adjunct to current therapies. Previous studies have shown antitumor effects of isoflavones in several cancers, including oral cancer. However, their mechanisms of action are still unclear. We hypothesized that isoflavones inhibit multiple signaling pathways implicated in oral carcinogenesis. To address our hypothesis, we investigated the effects of three isoflavone derivatives, genistein, biochanin A and daidzein, on SCC15 and SCC25 squamous cell carcinoma cell lines. In cell proliferation experiments, we found that genistein and biochanin A inhibited SCC15 and SCC 25 cell growth with an IC50 of $50 \mu \mathrm{M}$. We also investigated the effect of isoflavones on ERK and Akt pathways. Our results, from western blot analysis, suggest that both genistein and biochanin A induced decreases in phosphorylation of ERK and Akt at treatment concentrations of 20,50 and $100 \mu \mathrm{M}$. Taken together, our results clearly demonstrate a differential regulation of signaling pathways by various isoflavones in OSCC cell lines. Thus, tumor progression models can be utilized to study the preventive and therapeutic roles of isoflavones in oral cancer cell lines.
\end{abstract}

Keywords: oral cancer - isoflavones - cell signalling - cancer prevention

\section{Introduction}

Worldwide, over 500000 cases of head and neck squamous cell carcinoma (HNSCC) are diagnosed each year, representing the sixth most common cancer, and a major cause of morbidity and mortality (1). It is largely a preventable disease either through primary prevention (lifestyle changes), secondary prevention (treatment of high-risk lesions), or tertiary prevention (prevention of second primary tumors) $(2,3)$. About $90 \%$ of HNSCC's are oral squamous cell carcinoma (OSCC). The associated high morbidity and mortality are largely attributable to late stage diagnosis and occurrence of second primary tumors.

For reprints and all correspondence: Alok Bhushan, Ph.D. 970 South 5th Ave., Stop 8288, Pocatello, Idaho 83209-8288, Office: Leonard Hall 215, USA. Tel: (208) 282-4408; Fax: (208) 282-3601;

E-mail: abhushan@otc.isu.edu
Despite significant advances in therapeutic strategies, the five-year survival rate for oral cancer remains at about $50 \%$ (4). Current efforts examining the molecular events underlying HNSCC tumor progression may present the opportunity to identify molecular markers of diagnostic and prognostic value, as well as novel therapeutic targets in this particular cancer type.

In general, the transformation of normal epithelium to SCC occurs in multiple steps, involving the sequential activation of oncogenes and inactivation of tumor suppressor genes $(5,6)$. Although progress has been made in the identification of the alteration of tumor suppressor genes and their related protein products in HNSCC, the nature of the proliferative pathways driving uncontrolled cell growth in this tumor type are still poorly defined, thus limiting our ability to identify mechanism-based therapeutic approaches for this disease. 


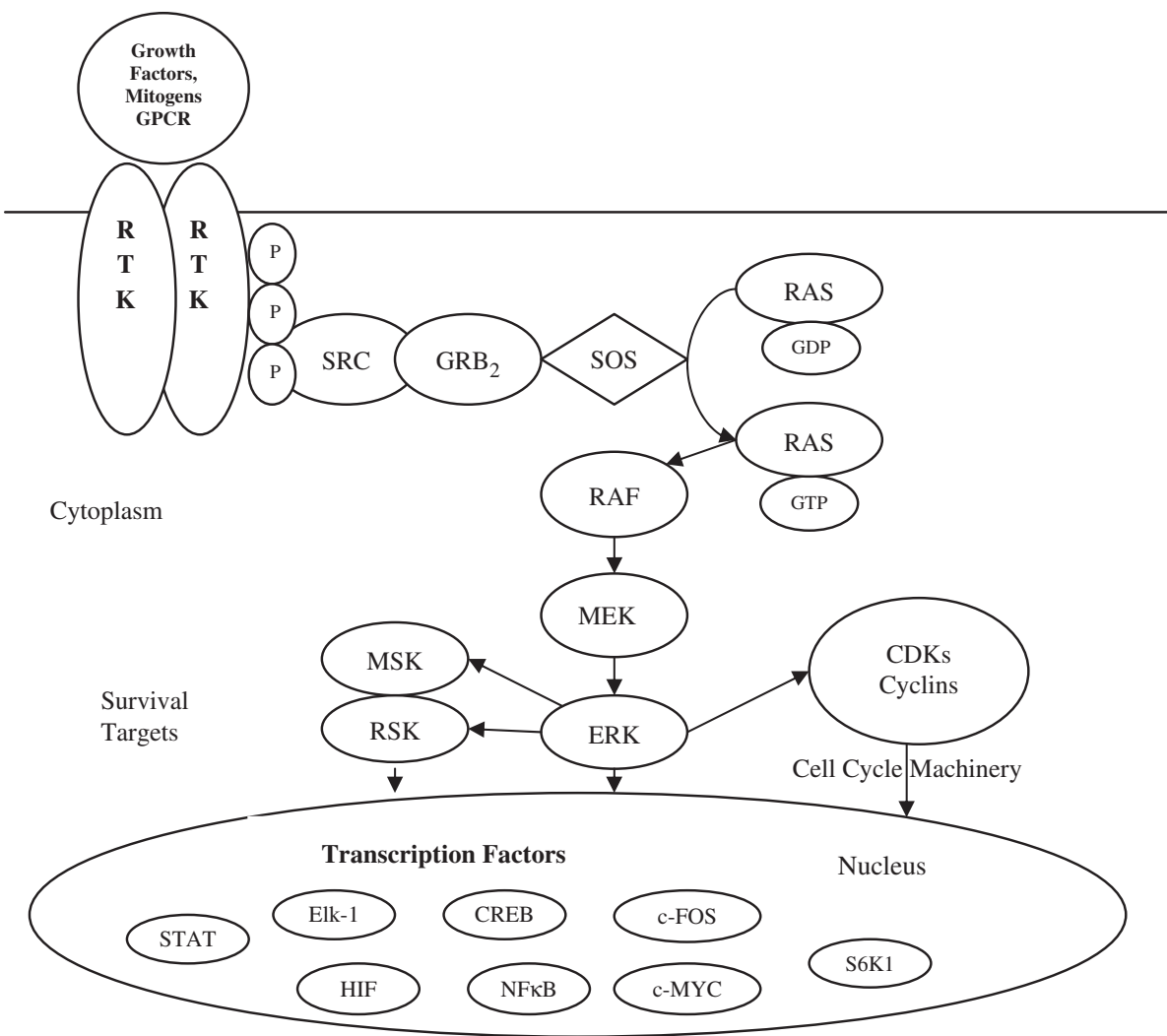

Figure 1. Receptor-linked tyrosine kinases such as the epidermal growth factor receptor (EGFR) are activated by extracellular ligands. Binding of epidermal growth factor (EGF) to the EGFR activates the tyrosine kinase activity of the cytoplasmic domain of the receptor. The EGFR becomes phosphorylated on tyrosines. Docking proteins such as GRB2 contain SH2 domains that bind to the phosphotyrosines of the activated receptor. BRB2 binds to the guanine nucleotide exchange factor SOS by way of and SH3 domain of GRB2. When the GRB2-SOS complex docks to phosphorylated EGFR, SOS becomes activated. Activated SOS promotes the removal of GDP from Ras. Ras can then bind GTP and become active. Activated Ras activates the protein kinase activity of RAF kinase. RAF kinase phosphorylates and activates MEK, which in turn phosphorylates and activates ERK (extracellular signal-regulated kinase) or mitogen-activated protein kinase (MAPK). The MAPK/ERK cascade may signal survival, cell growth and cell cycle progression. Its effect on RSK (ribosomal S6 kinase) and MSK (mitogen and stress-activated protein kinase) regulate the translational machinery, influencing cell growth and cell division.

Cells respond to extracellular stimuli by activating signaling cascades that lead to cellular responses. Mitogenactivated protein kinases (MAP kinases) are turned on in response to growth factors and promoters, resulting in proliferative signals (Fig. 1). Activation of epidermal growth factor receptor (EGFR) by EGF leads to progression of a growth response signal via the MAP kinase pathway (7). Mutation in HER-2/neu that codes for MAP kinase results in its constitutive phosphorylation and activation in HSC6 oral cancer cell line, showing the role of MAP kinase in oral cancer cell proliferation (8). In addition, the serine/threonine protein kinase Akt is a downstream target of phosphatidylinositol 3'-kinase (PI3K) and has been shown to be a key regulator of various cellular processes, including normal and aberrant cell growth and cell fate decisions such as differentiation and cell survival or death by apoptosis (Fig. 2). Akt promotes cell survival by phosphorylating proapoptotic and antiapoptotic proteins, including the $\mathrm{Bcl}-2$ family member BAD, caspase- 9 , and inactivation of tumor suppressor genes such as PTEN (9-11). Activated Akt has been shown to be a frequent event in several cancer types such as breast, colon and ovarian cancer $(9,12)$. Furthermore, evidence suggests that activated Akt accelerates tumor progression and promotes the malignant conversion of immortalized keratinocyte cell lines. Recent research indicates expression of phospho-Akt correlates with positive lymph node involvement in oral cancer patients (13).

Cancer treatment may be facilitated by the introduction of accepted therapies derived from natural products. Natural products have provided the basis for many of the pharmaceutical agents currently used in cancer therapy (14). The use of chemotherapeutic drugs in cancer therapy increases the risk of life threatening host toxicity; therefore, the search goes on to develop drugs, which selectively act on tumor cells. Vieira et al. (15) demonstrated that aqueous extracts from the plant Indigofera suffruticosa show antitumor effects in human epidermoid cancer cell lines with absence of cytotoxic effects. Flavonoids are polyphenolic compounds (Fig. 3) that occur ubiquitously in foods of plant origin and have been shown to have a variety of biological effects in numerous 


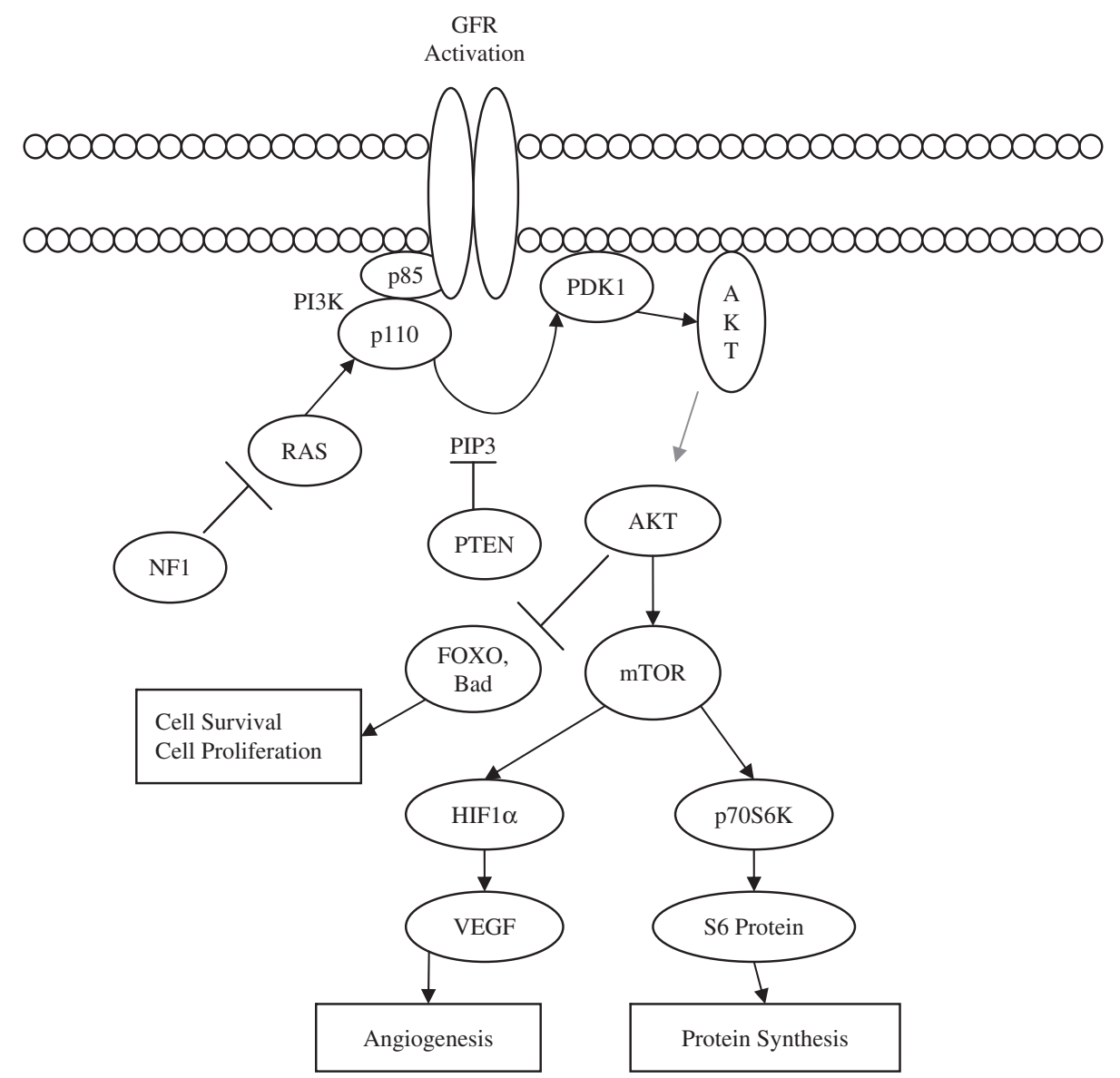

Figure 2. The serine/threonine kinase Akt, also known as protein kinase B (PKB), has become a major focus of attention because of its critical regulatory role in diverse cellular processes, including cancer progression. Activation of growth factor receptors (GFRs) is one of the major mechanisms responsible for upregulation of Akt signaling which in turn include activation of oncoproteins and inactivation of tumor suppressors intersecting the Akt signal transduction pathway. The Akt cascade is activated by receptor tyrosine kinases, and other stimuli that induce the production of phosphatidylinositol 3,4,5 triphosphates [PtdIns(3,4,5)P3P] by phosphoinositide 3-kinase (PI3K). These lipids serve as plasma membrane docking sites for proteins with pleckstrin-homology $(\mathrm{PH})$ domains, including Akt and its upstream activator PDK1. Akt regulates cell growth through its effects on the mTOR and p70 S6 kinase pathways, as well as cell cycle and cell proliferation through its direct action on CDK inhibitors and levels of cyclin D1. Akt is a major mediator of cell survival through direct inhibition of pro-apoptotic signals such as Bad and the Forkhead family of transcription factors.

mammalian systems (16). Genistein is a known protein kinase inhibitor; however, diadzein, which does not have a hydroxyl group at the 5- position of genistein, lacks inhibitory activity for protein tyrosine kinase (17). Flavinoids such as genistein and biochanin A may act at ATP-binding sites, although the precise inhibitory mechanism is not known $(18,19)$. Genistein is one of two major isoflavones in soy and has anti-proliferative effects on mitogen-stimulated growth of human breast cancer cells in culture (20). Genistein has shown antiproliferative effects in prostate cancer cells and antiangiogenic effect in OSCC via down-regulation of vascular endothelial growth factor (VEGF) $(21,22)$. Previous studies have revealed anti-tumor effects of isoflvones in several cancers, including oral cancer; however, their mechanisms of action are still unclear (23-25). Evidence suggests genistein can down-regulate the expression of about 11 genes including VEGF and can arrest cell growth and proliferation, invasion and angiogenesis (26).

We hypothesized isoflavones that inhibit tyrosine kinase activity can be used to prevent the molecular progression of OSCC through the inhibition of MAP kinase and Akt pathways. We tested this hypothesis by examining proliferation of isoflavone treated OSCC cells and determining the effects of isoflavones on MAP kinase and Akt protein expression in OSCC cells.

\section{Methods}

\section{Cell Cultures}

HNSCC cell lines SCC15 and SCC25 (American Type Culture Collection, Rockville, MD) were maintained in Dulbecco's Modified Eagle's Medium and Ham's 


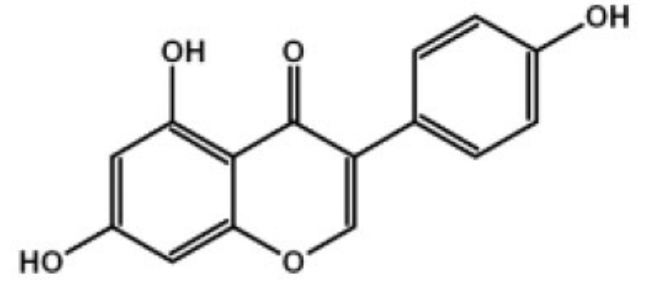

Genistein<smiles>O=c1c(-c2ccc(O)cc2)coc2cc(O)ccc12</smiles>

Daidzein

Figure 3. Chemical structure of genistein, biochanin A and daidzein.

Nutrient Mixture (DMEM/Ham's F12), 50:50 (v/v) supplemented with $10 \%$ Fetal Bovine Serum (FBS) (v/ v) and $400 \mathrm{ng} \mathrm{ml}^{-1}$ hydrocortisone in $5 \% \mathrm{CO}_{2}$ at $37^{\circ} \mathrm{C}$ according to ATCC propagation recommendations. Cells were split every 3 days at $70 \%$ confluence to continue growth. The cells were detached by treatment with sterile $0.25 \% \operatorname{trypsin} / 0.53 \%$ ethylenediamine tetraacetic acid (EDTA) and split into above medium according to ATCC subculturing recommendations. Cells were counted using a Coulter counter before being seeded into $75 \mathrm{ml}$ sterile tissue culture flasks for treatments.

\section{Pharmacological Treatments}

Genistein, biochanin A and daidzein ( $\geq 98 \%$ purity) stock solutions were prepared using dimethyl sulfoxide (DMSO) as the vehicle and diluted to the following concentrations: 5, 10, 20, 50 and $100 \mu \mathrm{M}$. Cells were treated with the preceding drug concentrations for $72 \mathrm{~h}$. The isoflavones listed above were purchased from SigmaAldrich (St. Louis, MO, catalog numbers G6649, D2016 and D7802, respectively).

\section{Antibodies}

The following antibodies were used in this study: rabbit polyclonal anti-ERK 1, anti-phospho-ERK, rabbit polyclonal anti-Akt and anti-phospho-Akt (Santa Cruz Biotechnology, Santa Cruz, CA).

\section{Western Blotting}

Cells were rinsed thrice in cold phosphate buffered saline (PBS), lysed with protein lysis buffer ( $\mathrm{pH}$ 7.6) containing protease inhibitor solution [sodium orthovandate $(200 \mathrm{mM})$, phenylmethanesulphonyl fluoride

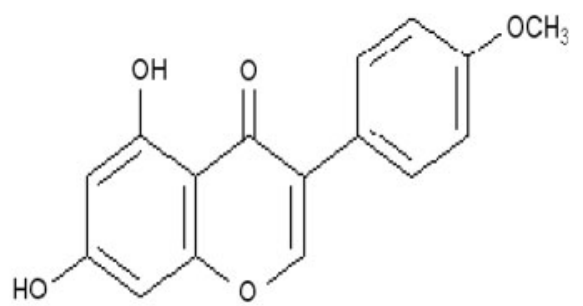

Biochanin A
(PMSF) $(100 \mathrm{mM})$, aprotonin $\left(1 \mathrm{mg} \mathrm{m}^{-1}\right)$ and leupeptin $\left(5 \mathrm{mg} \mathrm{m}^{-1}\right)$ ], scraped immediately, and transferred to microcentrifuge tubes. Lysates were sonicated for $10 \mathrm{~s}$. After centrifugation of the sonicated lysate at $10000 \times \mathrm{g}$ for $10 \mathrm{~min}$. at $4^{\circ} \mathrm{C}$, the resultant supernatant of the lysate was collected. The protein concentration was quantified using the Bradford protein assay kit (Bio-Rad, Hercules, CA) according to the manufacturer's instructions. Equivalent amounts of protein $(25 \mu \mathrm{g})$ were separated by SDS-PAGE and then transferred to polyvinylidene difluoride membranes. Membranes were then incubated for $1 \mathrm{~h}$ at room temperature with the blocking reagent $[5 \%$ milk, $2 \%$ BSA, $40 \mathrm{ml}$ Tris-buffered saline- $0.5 \%$ Tween-20 (TBST) pH 7.6], and then incubated overnight at $4{ }^{\circ} \mathrm{C}$ with the primary antibody (Santa Cruz Biotechnology, Santa Cruz CA). The membranes were washed thrice in TBST and incubated with anti-rabbit secondary antibody for $45 \mathrm{~min}$ at room temperature. After washing the membranes thrice with TBST, they were analyzed using SuperSignal West Pico chemiluminescent substrate (Pierce, Rockford, IL). The bands on the x-ray film were scanned and quantified using the Un-Scan-It image software (Un-Scan-It gel Version 5.1, Silk Scientific, Orem, UT).

\section{Cell Proliferation Assay}

Cell survival was assessed by formazan formation from the to tetrazolium salt. Cells $\left(5 \times 10^{3}\right)$ were cultured in flat-bottomed 96-well plates (Phenix Research Products, Hayward, CA) and treated with 2, 5, 10, 20, 50 and $100 \mu \mathrm{M}$ of genistein, biochnin A and daidzein, respectively. After incubation of the 96-well plates for $48 \mathrm{~h}$ at $37^{\circ} \mathrm{C}, 20 \mu \mathrm{l}$ of 3-(4,5-Dimethylthiazol-2-yl)-2,5-diphenyltetrazolium bromide (MTT) (Sigma-Aldrich, St. Louis, MO) solution $\left(5 \mathrm{mg} \mathrm{ml}^{-1}\right)$ was added to each well. The 


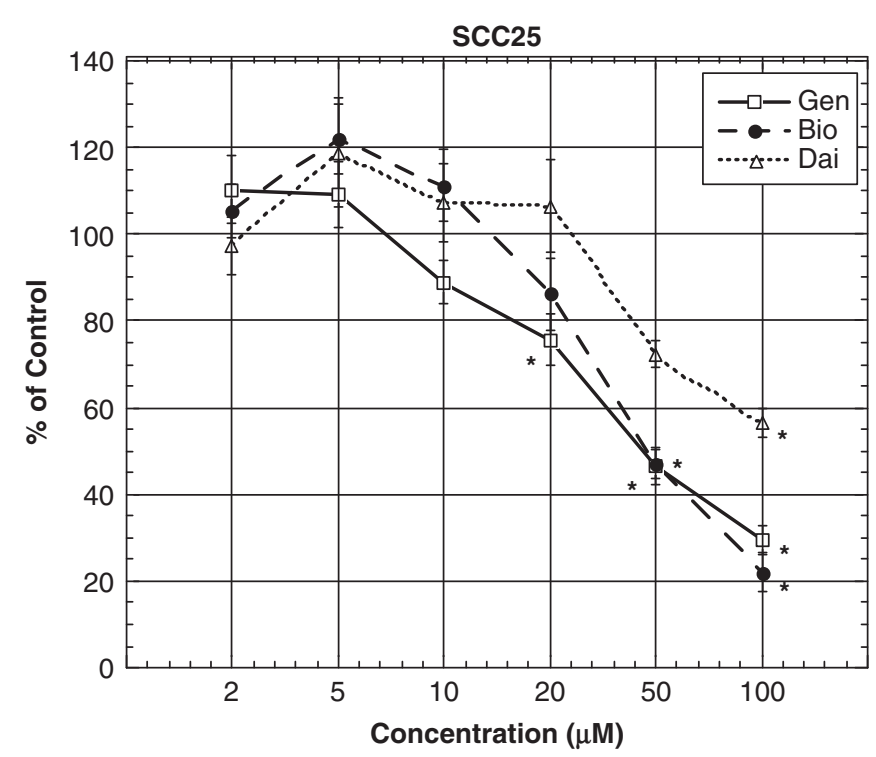

Figure 4. Treatment with genistein and biochanin $\mathrm{A}$ induced decreases in survival and proliferation in SCC25 cells. Cells (5000 cells per well) were seeded onto a 96-well plate and treated with $0,5,10,20,50$ and $100 \mu \mathrm{M}$ of genistein, biochanin A and dadzein, respectively for $72 \mathrm{~h}$. Cell survival was then determined by MTT assay. Data represent the mean $\pm \mathrm{SD}$ of at least three independent experiments. Statistical significance was determined by ANOVA and post hoc Tukey test. $\left({ }^{*} P<0.05\right)$. Abbreviations were: genistein, Gen; biochanin A, Bio; and daidzein, Dai.

plates were incubated for $4 \mathrm{~h}$. The medium was removed with a needle syringe and $100 \mu \mathrm{l}$ of DMSO added and pipetted to dissolve crystals. The absorbance of each well was measured at $570 \mathrm{~nm}$ using a plate reader (Synergy HT Multi-Detection Microplate Reader, Bio-Tek Instruments, Inc., Winooski, VT).

\section{Statistical Analysis}

ANOVA followed by the post hoc Tukey test was used to determine the differences between groups of the data obtained from the MTT assay and western blot by using KaleidaGraph (Synergy Software for Windows and Macintosh, Reading, PA). $P$-values $<0.05$ were considered statistically significant.

\section{Results}

\section{Isoflavones Decrease Oral Cancer Cell Survival}

We investigated the effect of genistein, biochanin A and daidzein on survival of SCC25 cells. Figure 4 shows that treatment with all three isoflavones induced decreases in survival of OSCC cells in a concentration-related manner at concentrations higher than $20 \mu \mathrm{M}$. The rank order of the effect of the isoflavones studied was: genistein $\geq$ biochanin $\mathrm{A}>>$ daidzein (Fig. 4). The $\mathrm{IC}_{50}$ values
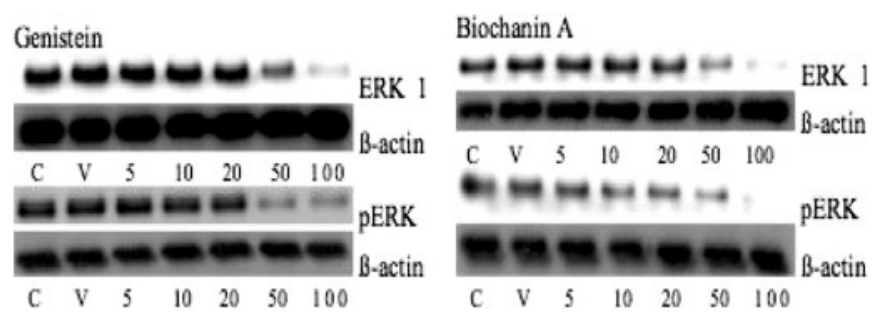

Figure 5. Western blot analysis of total and phosphorylated ERK1 protein in cell lysates from SCC15 cells treated with genistein and biochanin A. Cells were treated with genistein and biochanin A, respectively, at $5,10,20,50$ and $100 \mu \mathrm{M}$, for $72 \mathrm{~h}$. $B$-actin was used as an internal control.

(i.e. the treatment concentration that gave rise to a $50 \%$ decrease in cell survival) for both genistein and biochanin A were $\sim 50 \mu \mathrm{M}$ (Fig. 4).

\section{Genistein and Biochanin A Suppress Cell Proliferation in OSCC Cells}

Activation of the MAP kinase signaling pathway resulting in phosphorylation of ERK1/2 is one of the regulatory pathways implicated in controlling cell growth in response to ligand binding and dimerization of EGFR. Since MAP kinase plays a role in oral cancer cell proliferation, we determined the effect of genistein, biochanin $\mathrm{A}$ and daidzein on the protein expression of this signaling pathway in SCC15 cells using western blotting. Our results indicate that genistein and biochanin A treatment for $72 \mathrm{~h}$ induced decreases in the expression of total ERK at 50 and $100 \mu \mathrm{M}$ (Figs 5 and 6a). Phosphorylated ERK protein expression was also decreased when SCC15 cells were treated with genistein and biochanin A for $72 \mathrm{~h}$ at 50 and $100 \mu \mathrm{M}$ (Figs 5 and 6b). Treatment of SCC15 cells with biochanin A for $72 \mathrm{~h}$ showed a pattern of results similar to those obtained with genistein treatment, but with more pronounced decrease in total ERK protein expression when cells were treated $50 \mu \mathrm{M}$ biochannin A (Fig. 6a). However, treatment of SCC15 cells with daidzein did not lead to any change in ERK or pERK expression (data not shown).

\section{Analysis of Akt Protein Expression: Genistein and Biochanin A Curb Cell Survival}

Inappropriate activation of the PI3K/Akt pathway is a crucial step leading to cell survival and motility and angiogenesis. We therefore investigated the effect of genistein, biochanin A and daidzein on Akt protein expression in SCC25 cells by western blot analysis. Treatment of these cells with genistein and biochanin A induced lowering of Akt and pAkt expression at 50 and $100 \mu \mathrm{M}$ (Figs 7, 8a and b). However, treatment of these cells with daidzein at similar concentrations (i.e. 5-100 $\mu \mathrm{M}$ ) did not induce any changes in their Akt and pAkt expression (data not shown). 

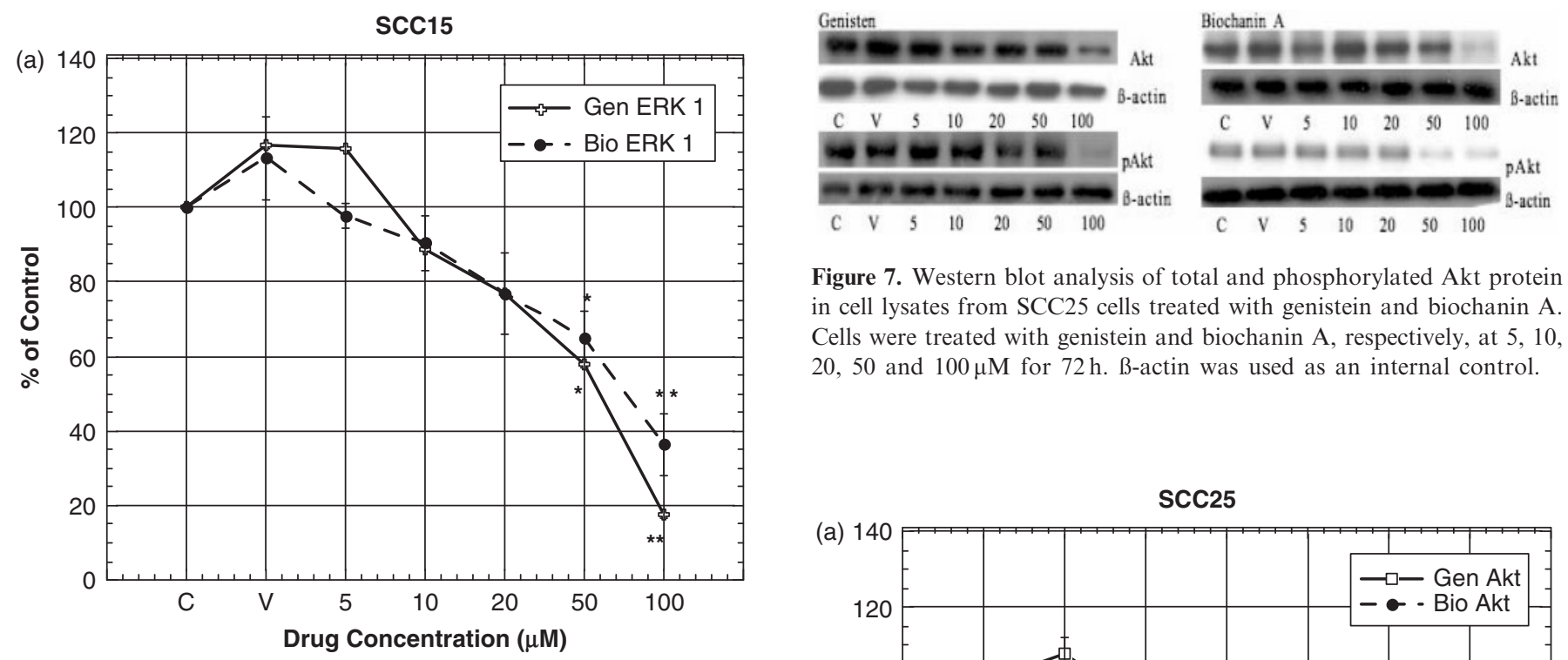

Figure 7. Western blot analysis of total and phosphorylated Akt protein in cell lysates from SCC25 cells treated with genistein and biochanin A. Cells were treated with genistein and biochanin A, respectively, at 5, 10, 20,50 and $100 \mu \mathrm{M}$ for $72 \mathrm{~h}$. B-actin was used as an internal control.
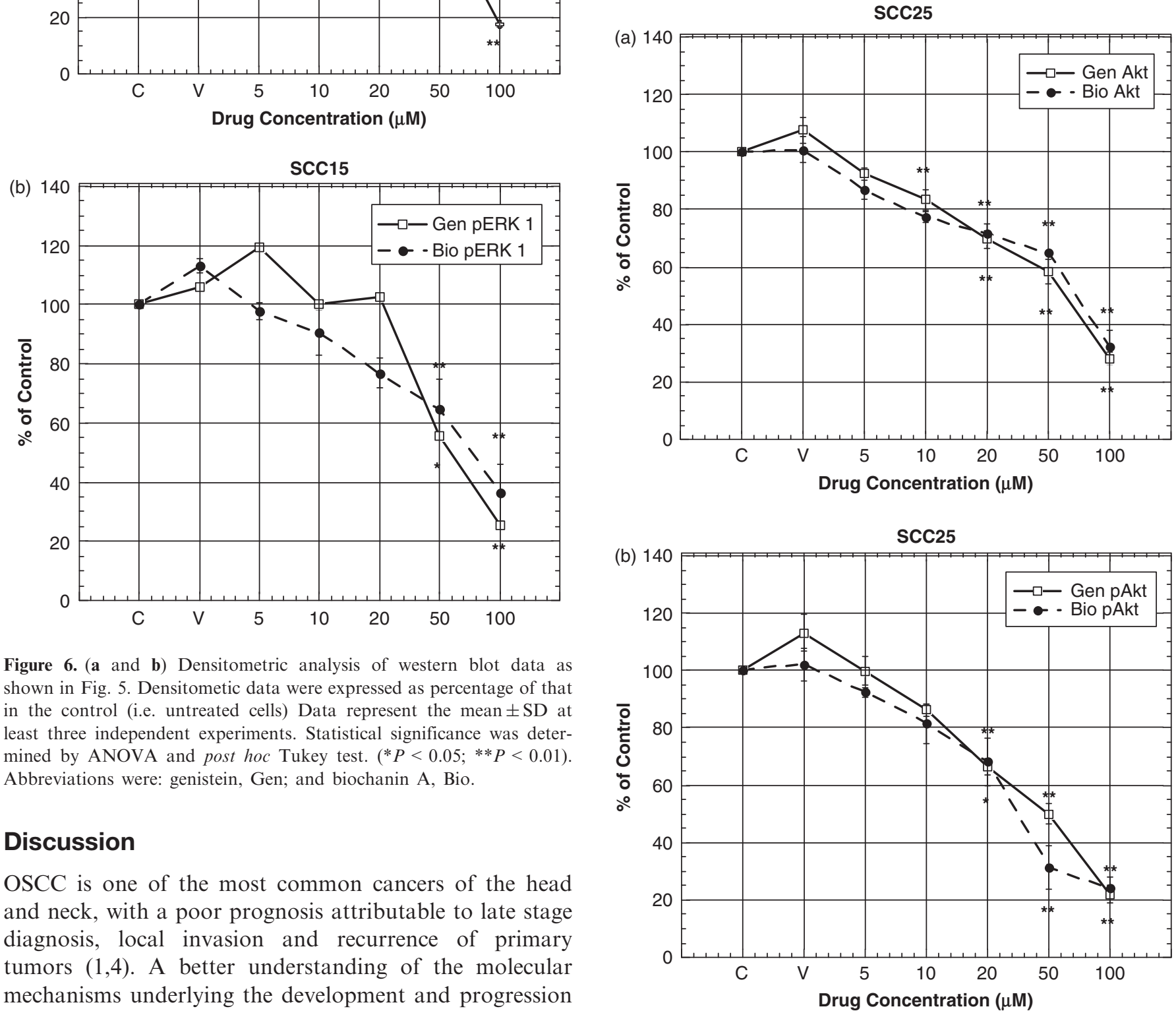

Figure 6. (a and b) Densitometric analysis of western blot data as shown in Fig. 5. Densitometic data were expressed as percentage of that in the control (i.e. untreated cells) Data represent the mean $\pm S D$ at least three independent experiments. Statistical significance was determined by ANOVA and post hoc Tukey test. $\left({ }^{*} P<0.05 ; * * P<0.01\right)$. Abbreviations were: genistein, Gen; and biochanin A, Bio.

\section{Discussion}

OSCC is one of the most common cancers of the head and neck, with a poor prognosis attributable to late stage diagnosis, local invasion and recurrence of primary tumors $(1,4)$. A better understanding of the molecular mechanisms underlying the development and progression of OSCC may help identify novel targets for pharmacological intervention and chemoprevention of this disease $(2,3)$. In this regard, the milieu of signal transduction pathways whose aberrant activity promotes the unregulated growth and survival of OSCC cells has just begun to be elucidated. These include the over-expression of

Figure 8. (a and b) Densitometric analysis of western blot data as shown in Fig. 7. Densitometic data were expressed as percentage of that in the control (i.e. untreated cells) Data represent the mean $\pm \mathrm{SD}$ at least three independent experiments. Statistical significance was determined by ANOVA and post hoc Tukey test. (* $P<0.05$; $* * P<0.01)$. Abbreviations were: genistein, Gen; and biochanin A, Bio. 
EGFR, the sustained phosphorylation of MAP kinase, and persistent activation of the Akt pathway $(9,25,27)$. In this study, we clearly demonstrated that treatment with the isoflavones, genistein and biochanin A, could significantly decrease the in vitro proliferation of SCC15 and SCC25 cells, with a similar $\mathrm{IC}_{50}$ value for both genistein and biochanin $\mathrm{A}$ at $\sim 50 \mu \mathrm{M}$. Thus, our results are similar to those of Myoung et al. (22) who had also demonstrated the cytotoxic effect of genistein in oral squamous carcinoma cells. Additionally, Alhasan et al. (28) report genistein induced cell growth inhibition and apoptosis in a HNSCC cell line. Consistent with the above findings in OSCC is the observation of Davis et al. (29) who noted the antiproliferative effect of genistein in prostate cancer cells and genistein's effect in lowering prostate specific antigen expression. Similarly, Su et al. (30) showed that treatment of bladder cancer cells with biochanin A resulted in decreases in cell growth, with an IC50 of $30 \mu \mathrm{g} \mathrm{ml}^{-1}$ (i.e. $20 \mu \mathrm{M}$ ) and directly induced apoptosis in those cells. Furthermore, treatment with deguelin, a flavinoid, inhibited the growth of and induced apoptosis in premalignant and malignant human bronchial epithelial (HBE) cells but had minimal effects on normal HBE cells (31). All in all, results of this study, as well as those discussed above, strongly suggest that isoflavones exert an antiproliferative effect on a variety of cancer cell types, and this outcome may be related to their effect(s) on signaling pathways such as MAP kinase and Akt.

Most types of cancers exhibit constitutive activity of the ERK MAP kinase protein, conferring increased proliferation and resistance to apoptotic stimuli $(32,33)$. Constitutive phosphorylation of MAP kinase represents a common deregulated signaling route in $\operatorname{OSCC}(34,35)$. One objective of our study was to determine whether isoflavones exert inhibitory effects on this pathway in SCC15 and SCC25 cell lines, particularly that of phosphorylated ERK. Our results visibly establish that treatment of these two cell lines with genistein and biochanin A induced a lowering of total ERK and phosphorylated ERK protein expression in a doserelated manner. Consistent with our findings is the recent observation that treatment with genistein and kaempferol, which is a natural flavonoid derived from tea, broccoli and other plant sources, blocked induced activator protein 1 activity in human prostrate cancer cells (36). Moreover, survival signals, including ERK and Akt, may be involved in determining the radiosensitivity of human esophageal cancer cells, and genistein treatment of these cells may enhance their radiosensitivity via inhibition of their survival signals (37).

Others have shown that pharmacologic and genetic approaches targeting Akt suppress the proliferation of premalignant and malignant human epithelial cells, including reversal of characteristics of HBE cells (31), In this study, we have demonstrated the inhibitory effect of genistein and biochanin A on Akt and phosphorylated
Akt in two OSCC cell lines: thus, our results suggest these agents could be useful chemopreventive agents and may also be employed as chemotherapy for oral cancer. Inhibition of PC-3 cells by genistein via repression of the Akt pathway is another indication of isoflavones as chemopreventive/therapeutic agents in the suppression of carcinogenesis and cancer cell proliferation (38). Consistent with this notion is the evidence, in vivo, that genistein potentiated the gemcitabine-induced killing by down-regulation of NF- $\mathrm{KB}$ and Akt (39). Further support can be derived from the observation that genistein, biochanin A and kaempferol potently inhibited ERK1/2 and Akt phosphorylation in a rat prostate cancer cell line (40).

Because of our finding that both genistein and biochanin A inhibit cell proliferation in OSCC cell lines and their MAP kinase and Akt signaling pathways, our results may have interesting therapeutic implications and applications. For example, they prompt us to propose isoflavone compounds as oral cancer chemopreventive and/or chemotherapeutic agents. Consequently, further elucidation of effects of isoflavones on regulation of expression of oncogenes and tumor suppresser genes will greatly enhance our understanding of the mechanistic roles isoflavones play in inhibiting carcinogenesis. More importantly, in contrast to some agents presently used in oral cancer chemoprevention and therapy, genistein and biochanin A may provide more effective but less toxic alternatives to conventional chemotherapy. In conclusion, our findings, together with those discussed above, strongly suggest that the antitumor potential of both genestein and biochanin A should be tested in vivo and, in particular, in clinical trials of OSCC chemoprevention and/or chemotherapy. Nevertheless, further studies are clearly needed to comprehensively assess the value of isoflavones in human cancer prevention and/or treatment.

\section{Acknowledgements}

NIH P20 RRI6454 Grant and MSTMRI Grant, and the American Foundation For Pharmaceutical Education supported our studies, in part.

\section{References}

1. Mignogn MD, Fedele S, Russo LL. The world cancer report and the burden of oral cancer. Eur J Cancer Prev 2004;13:139-42.

2. Scheer M, Kuebler AC, Zoller JE. Chemoprevention of oral squamous cell carcinomas. Onkologie 2004;27:187-93.

3. Lippman SM, Sudbo J, Hong WK. Oral cancer prevention and the evolution of molecular-targeted drug development. J Clin Oncol 2005;23:346-56.

4. Chin D, Boyle GM, Porceddu S, Theile DR, Parsons PG, Coman WB. Head and neck cancer: past, present and future. Expert Rev Anticancer Ther 2006;6:1111-8.

5. Walker DM, Boey G, McDonald LA. The pathology of oral cancer. Pathology 2003;35:376-83.

6. Wong DT, Todd R, Tsuji T, Donoff RB. Molecular biology of human oral cancer. Crit Rev Oral Biol Med 1996;7:319-28. 
7. Scaltriti M, Baselga J. The epidermal growth factor pathway: a model for targeted therapy. Clin Cancer Res 2006;12:5268-72.

8. Arvind R, Shimamoto H, Momose F, Amagasa T, Omura K, Tsuchida N. A mutation in the common docking domain of ERK2 in a human cancer cell line, which was associated with its constitutive phosphorylation. Int J Oncol 2005;27:1499-504.

9. Vivanco I, Sawyers CL. The phosphatidylinositol 3-kinase AKT pathway in human cancer. Nat Rev Cancer 2002;2:489-501.

10. Amornphimoltham P, Sriuranpong V, Patel V, Benevides F, Conti CJ, Sauk J, et al. Persistent activation of the Akt pathway in head and neck squamous cell carcinoma: a potential target for UCN-01. Clin Cancer Res 2004;10:4029-37.

11. Powis G, Ihle N, Kirkpatrick DL. Practicalities of drugging the phosphatidylinositol-3-kinase/Akt cell survival signaling pathway. Clin Cancer Res 2006;12:2964-6.

12. Cheng JQ, Linsley CW, Cheng GZ, Yang H, Nicosia SV. The Akt/ PKB pathway: molecular targets for cancer drug discovery. Oncogene 2005;24:7482-92.

13. Lim J, Kim JH, Paeng JY, Kim MJ, Hong SD, Lee JI, et al. Prognostic value of activated Akt expression in oral squamous cell carcinoma. J Clin Pathol 2005;58:1199-205.

14. Pietras RJ, Weinberg OK. Antiangiogenic steroids in human cancer therapy. Evid Based Complement Alternat Med 2005;2:49-57.

15. Vieira JRC, de Souza IA, do Nascimento SC, Leite SP. Indigofera suffruticosa: an alternative anticancer therapy. Evid Based Complement Alternat Med 2007:4:355-9.

16. Branca F, Lorenzetti S. Health effects of Phytoestrogens. Forum Nutr 2005;57:100-11.

17. Nakashima S, Koike T, Nozawa Y. Genistein, a protein tyrosine kinase inhibitor, inhibits thromboxane A2-mediated human platelet responses. Mol Pharmacol 1991;39:475-80.

18. Azuma Y, Onishi Y, Sato Y, Kizaki H. Effects of protein tyriosine kinase inhibitors with different modes of action on topoisomerase activity and death of IL-2-dependent CTLL-2 cells. J Biochem $1995 ; 118: 312-8$.

19. Akiyama T, Ishida J, Nakagawa S, Ogawara H, Watanabe S, Shibuya M. Genistein, a specific inhibitor of tyrosine-specific protein kinases. J Biol Chem 1987;262:5592-5.

20. Shon YH, Park SD, Nam KS. Effective chemopreventive activity of genistein against human breast cancer cells. J Biochem Mol Biol 2006;39:448-51.

21. Wang J, Eltoum IE, Lamartiniere CA. Genistein alters growth factor signaling in transgenic prostate model (TRAMP). Mol Cell Endocrinol 2004;219:171-80.

22. Myoung H, Hong SP, Yun PY, Lee JH, Kim MJ. Anti-cancer effect of genistein in oral squamous cell carcinoma with respect to angiogenesis and in vitro invasion. Cancer Sci 2003;94:215-20.

23. Gerhauser C, Klimo K, Heiss E, Neumann I, Gamal-Eldeen A, Knaft J, et al. Mechanism-based in vitro screening of potential cancer chemopreventive agents. Mutat Res 2003;523-524:163-72.

24. Alhasan SA, Ensley JF, Sarkar FH. Genistein induced molecular changes in a squamous cell carcinoma of the head and neck cell line. Int $J$ Oncol 2000;16:333-8.

25. Hiraishi Y, Wada T, Nakatani K, Negoro K, Fujita S. Immunohistochemical expression of EGFR and p-EGFR in oral squamous cell carcinomas. Pathol Oncol Res 2006;12:151-60.
26. Ravindranath MH, Muthugounder S, Presser N, Viswanathan S. Anticancer therapeutic potential of soy isoflavone, genistein. $A d v$ Exp Med Biol 2004;546:121-65.

27. Ghosh S, Munshi HG, Sen R, Linz-McGillem LA, Goldman RD, Lorch $\mathbf{J}$, et al. Loss of adhesion-regulated proteinase production is correlated with invasive activity in oral squamous cell carcinoma. Cancer 2002;38:468-74.

28. Alhasan SA, Ensley JF, Sarkar FH. Genistein induced molecular changes in a squamous cell carcinoma of the head and neck cell line. Int J Oncol 2000;16:333-8.

29. Davis JN, Kucuk O, Sarkar FH. Expression of prostate-specific antigen is transcriptionally regulated by genistein in prostate cancer cells. Mol Carcinog 2002;34:91-101.

30. Su SJ, Yeh TM, Lei HY, Chow NH. The potential of soybean foods as a chemoprevention approach for human urinary tract cancer. Clin Cancer Res 2000;6:230-6.

31. Chun KH, Kosmeder JW, Sun S, Pezzuto JM, Lotan R, Hong WK, et al. Effects of deguelin on the phosphatidylinositol 3-kinase/Akt pathway and apoptosis in premalignant human bronchial epithelial cells. J Natl Cancer Inst 2003;95:291-302.

32. Zhuang S, Schnellmann RG. A death-promoting role for extracellular signal-regulated kinase. J Pharmacol Exp Ther 2006; 319:991-7.

33. Rubinfeld H, Seger R. The ERK cascade: a prototype of MAPK signaling. Mol Biotechnol 2005;31:151-74.

34. Mishima K, Yamada E, Masui K, Shimokawara T, Takayama K, Sugimura $\mathrm{M}$, et al. Overexpression of the ERK/MAP kinases in oral squamous cell carcinoma. Mod Pathol 1998;11:886-91.

35. Mukhopadhyay S, Munshi HG, Kambhampati S, Sassano A, Platanias LC, Stack MS. Calcium-induced matrix metalloproteinase 9 gene expression is differentially regulated by ERK $1 / 2$ and p38 MAPK in oral keratinocytes and oral squamous cell carcinoma. J Biol Chem 2004;279:33139-46.

36. Gopalakrishnan A, Xu CJ, Nair SS, Chen C, Hebbar V, Kong AN. Modulation of activator protein-1 (AP-1) and MAPK pathway by flavonoids in human prostrate cancer PC3 cells. Arch Pharm Res 2006:29:633-44.

37. Akimoto T, Nonaka T, Ishikawa H, Sakurai H, Saitoh JI, Takahashi T, et al. Genistein, a tyrosine kinase inhibitor, enhanced radiosensitivity in human esophageal cancer cell lines in vitro: possible involvement of inhibition of survival signal transduction pathways. Int J Radiat Oncol Biol Phys 2001;50:195-201.

38. Cao F, Jin TY, Zhou YF. Inhibitory effect of isoflavones on prostate cancer cells and PTEN gene. Biomed Environ Sci 2006; 19:35-41.

39. Banerjee S, Zhang Y, Ali S, Bhuyian M, Wang Z, Chiao PJ, et al. Molecular evidence for increased antitumor activity of gemcitabine by genistein in vitro an in vivo using an orthotopic model of pancreatic cancer. Cancer Res 2005;65:9064-72.

40. Wang S, DeGroff VL, Clinton SK. Tomato and soy polyphenols reduce insulin-like growth factor-I-stimulated rat prostate cancer cell proliferation and apoptotic resistance in vitro via inhibition of intracellular signaling pathways involving tyrosine kinase. $J$ Nutr 2003:133:2367-76

Received June 18, 2007; accepted January 16, 2008 


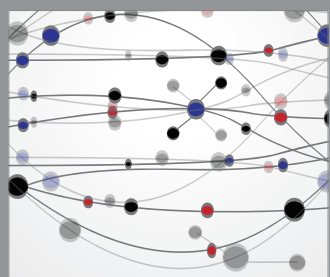

The Scientific World Journal
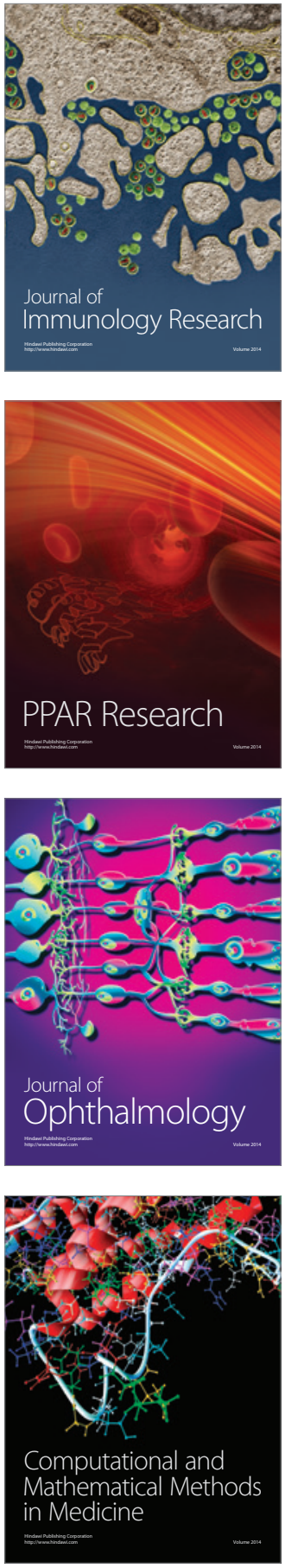

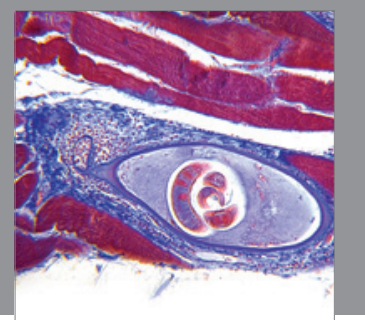

Gastroenterology

Research and Practice
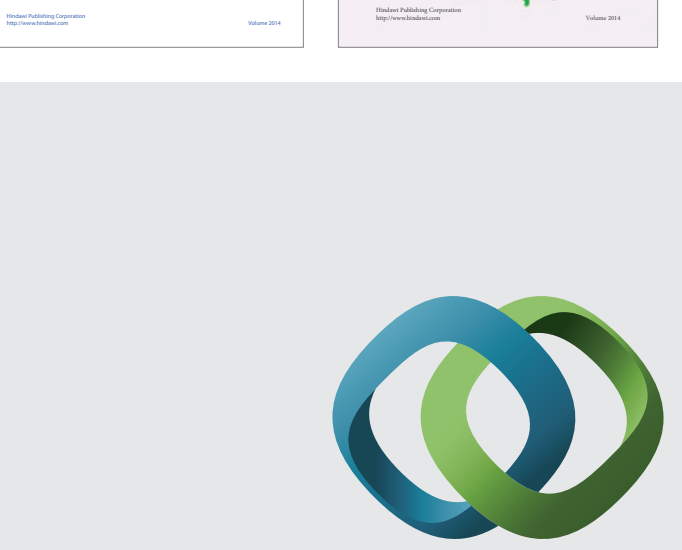

\section{Hindawi}

Submit your manuscripts at

http://www.hindawi.com
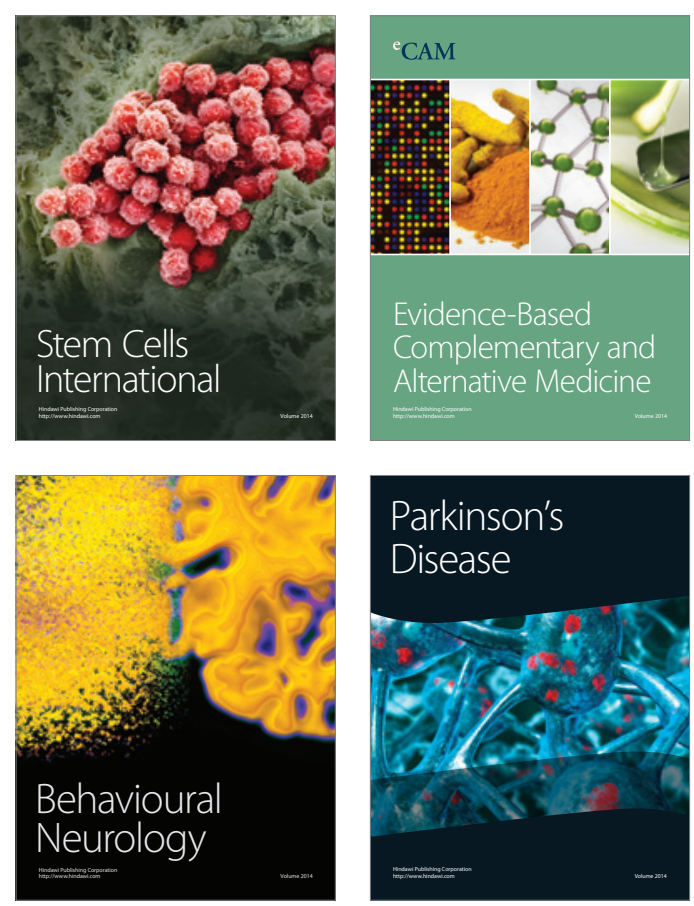

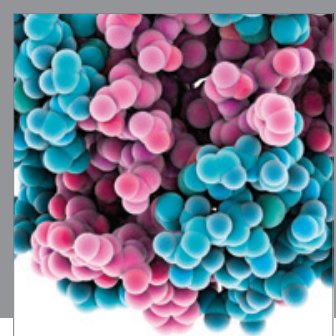

Journal of
Diabetes Research

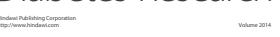

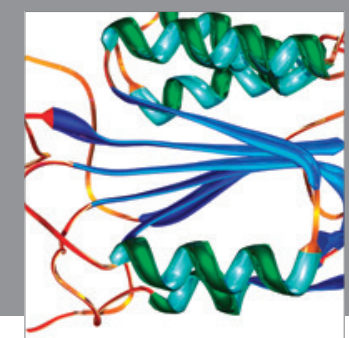

Disease Markers
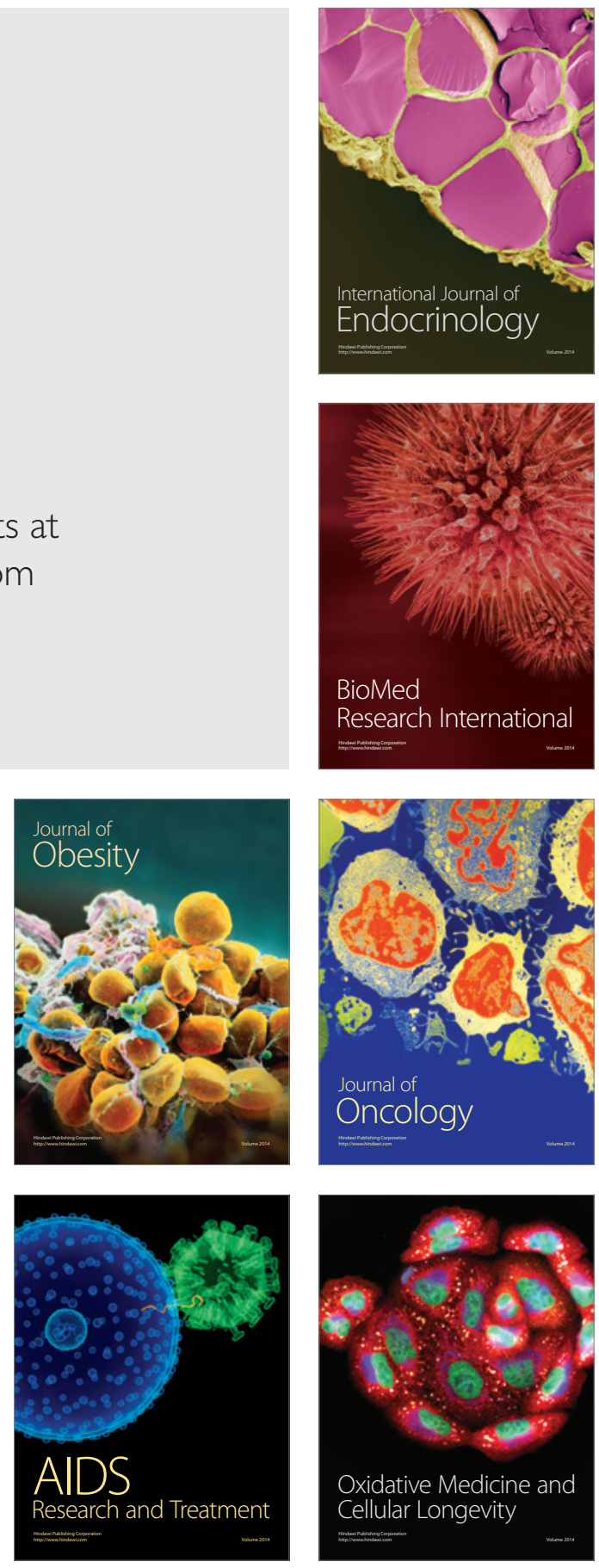